\title{
Analysis on the Elements of the Internet Era Enterprise Market
}

\author{
Yu Shuang ${ }^{1, a}$, Liu Jianqing ${ }^{2, b}$, Deng Yaqing ${ }^{3, c}$ \\ ${ }^{1}$ Baoding Vocational and Technical College; Baoding \\ ${ }^{2}$ Baoding Vocational and Technical College; Baoding \\ ${ }^{3}$ Baoding Vocational and Technical College; Baoding \\ a Ysh5665@sina.com, b Ysh5665@sina.com, ${ }^{c}$ Ysh5665@sina.com
}

Keywords: Internet; market; analysis of factors

\begin{abstract}
In today's world, IT has penetrated into all aspects of society and dramatically changed the mode of social production and life, as a business, in order to survive and develop in the reality, we must closely follow the trend and strengthen the understanding of faced environment and provide targeted solutions and guidelines. In this paper, the authors closely linked to this theme and analyzed and dissected through essential elements of Internet age enterprise market and provide a reference for better development of enterprises.
\end{abstract}

\section{Background}

The development of 21st century can be equivalent to the development of information technology, and the most widely performance and application form of the latter is the Internet. At present, make the mobile terminals of notebook computers, tablet PCs, smart phones as the media and the Internet almost penetrate into every moment of daily life, accompanying with which, the network business model by the platform of mobile terminal has also been considerably developed. According to iResearch data show, 2013 Chinese Internet trading volume has reached 1.85 trillion yuan, which reaches an increase of $42.0 \%$ over the previous year and accounted for $7.8 \%$ of total social retail sales and reaches an increase of 1.6 percent over the previous year and the rise reaches 25 percent. With the further maturation of Internet-related construction, the figure is expected to break through 4 trillion yuan to 2016. Thus, the Internet business operations has become a vital part of our society business operations. Any business wants to foothold in today's society, survive and develop and had better learn to adapt and use the emerging market model of Internet.

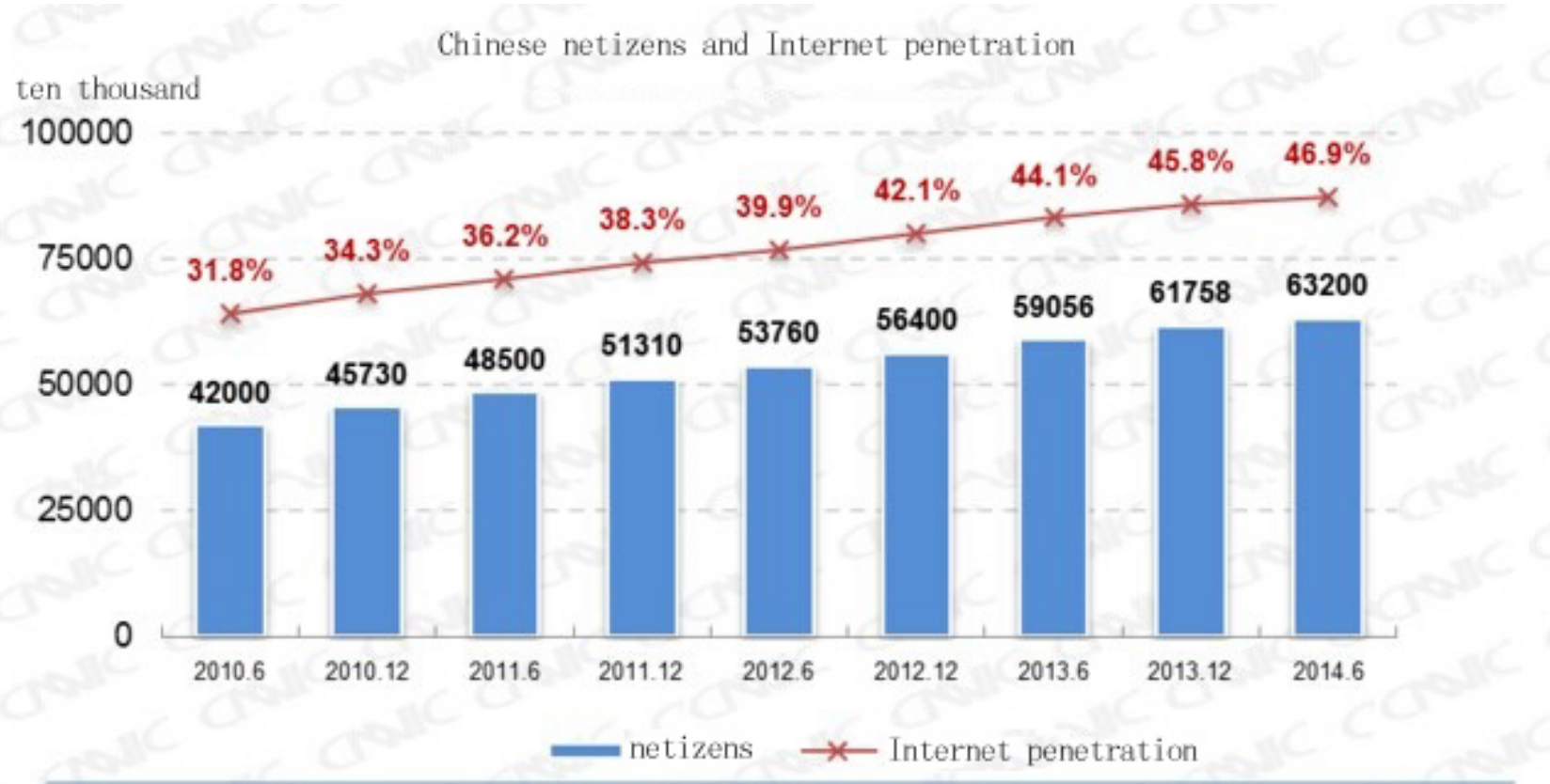




\section{The main affecting factors of Internet business market}

\section{Main consumer psychology factors}

Network marketing is built on IT platform, so consumers must have the appropriate IT skills and hardware support. Several survey data studies have found that online consumer's age and spending power has an important association. The distribution of Internet users' age represents of the network consumers' age distribution to a large extent. As is shown below, we can see from the data that our network consumer groups are mainly concentrated in the eighteen to thirteen years old, and that this part of the population shows a growth trend. This age group has a more solid economic foundation and a stronger ability of receiving network marketing.

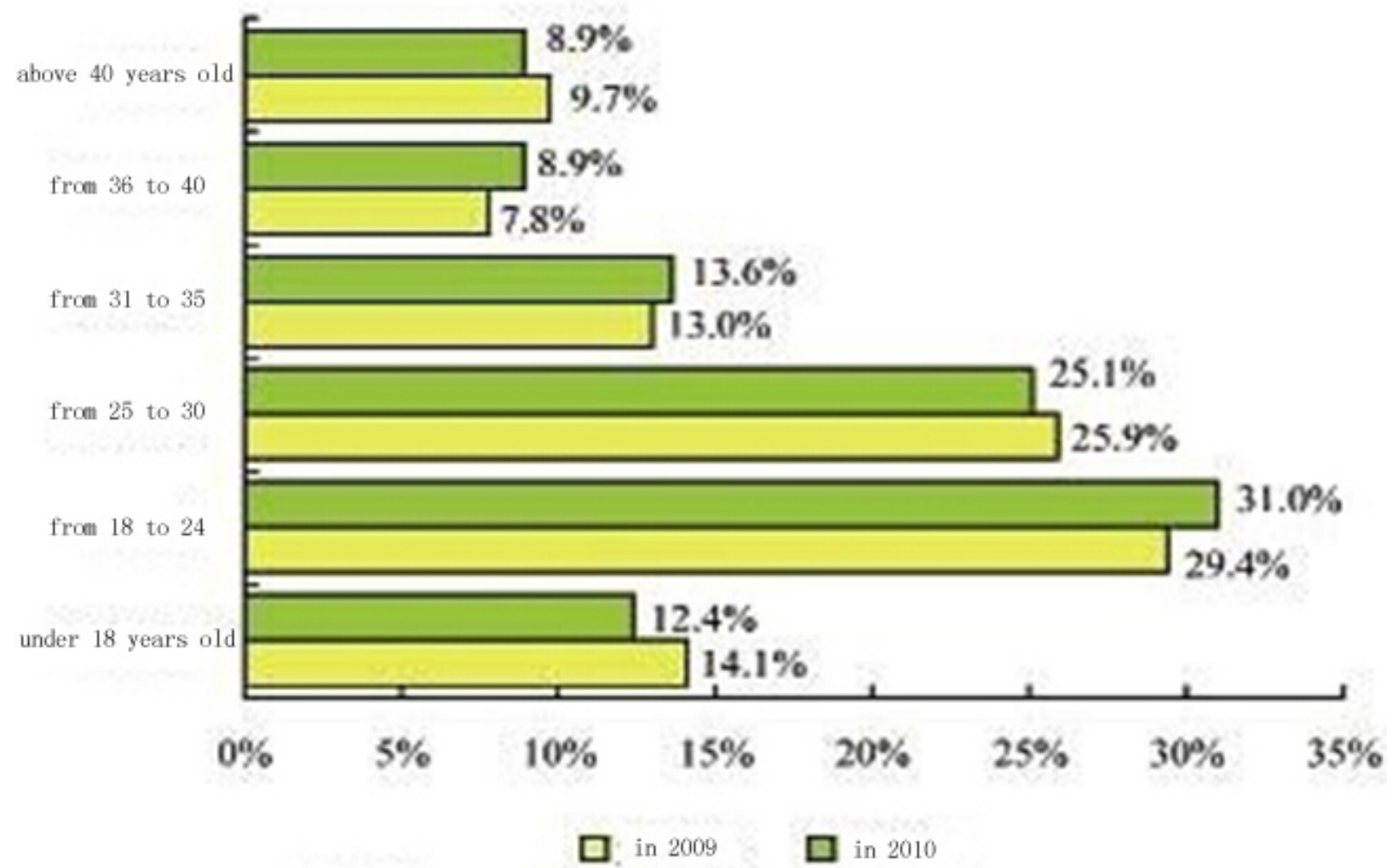

Therefore, the main members of current network consumption concentrated in the youth population. The main features of this group are that the education quality is relatively high and the pursuit of new things, prominent self-awareness, the requirement of personalization and characterization, the following of the trend and no lack of intellect, lack of patience degree and so on. To get their support, we must fully understand the consumer psychology of the main consumer to take targeted measures to open markets.

In addition, in recent years, middle-aged and juvenile network consumer groups have been gradually rising, but overall, whose market share account is small and can be referred to a secondary factor.

\section{The main consumer consuming elements}

In conclusion, the network consumer groups can basically self-support economy and has a relatively strong consuming power, consumer motivation mostly departs from himself. A 2008 statistics show that the average income of the consumer network is 203.6 yuan, which is 400 yuan higher than the overall income of the residents and 350 yuan higher than the magazine audience (the highest income group in traditional media audiences), which means that the network market itself has focused on the highest consuming groups in daily consumption productions. Judging from the consuming content, electronics, jewelry, clothing are centralized objects of network consumption. The statistics also show that the number of ownership of network of consumers digital cameras, smart phones and family car is far more than the national average household level, which can be 
seen from Jingdong Mall data which is mainly electrical sales. In 2013, PC sales in Jingdong Mall have been more than 160,000 units and the total annual sales are more than one hundred billion, of which $30 \%$ is more than 6000 yuan high-end computer productions. This is further evidence that such a large network consumption needs to consider the consumption ability of consumer groups and reform network platform business model.

\section{Network platform business model factors}

Internet marketing can be developed into the marketing model in a few years that can compete with the main consumer and naturally has its unique feature. The first feature, which is the most important feature of network marketing, breaks the boundaries of geography and time, achieve a borderless interface between business and customer. Network platform allows customers to consume online anytime 24 hours a day, which greatly extend the consuming time of consumer and increase consumption. Secondly, through the network platform, businesses in exotic can also transact with local consumers, which greatly expands the company's market-oriented and provides more opportunities; third, network marketing autonomously mobilize media display by customer, that is, the store is sent to the customer's home, which greatly saves the customer's time and energy, reduce their shopping costs and thereby effectively increases the interest and the frequency of shopping. Fourth, through independent information platform, customers can achieve alone, privatization shopping mode, which helps them to concentrate more to get a better shopping experience. Many people can not tolerate physical store sales tracking service of personnel to give up shopping, and the Internet is just to meet consumer demand of this part of the population.Fifth, the network marketing omits the other second and third-party platform except for customers and businesses, avoided the communication errors caused by multi-media to a large extent, and save communication costs, improving the economic benefits to some extent; Finally, the unique search engine service of network platform provides consumers with fast positioning requirements goods means, through measures such as keyword search, related productions recommendations and so on to initiative meet the needs of users and their potential needs to enhance customer satisfaction and thus promote the consumption levels.

\section{The specific development strategies of Internet market}

\section{Do well in production positioning}

One feature of Internet sales is personalized and specialized production categories. In most cases, Internet consumers do network consumption with a certain purpose. Therefore, in terms of the characteristics of strong purpose consumption by online consumers, identify their product positioning, precisely and concisely describe it is the premise and foundation of getting consumers attention and buying behavior. In online shopping, the consumers get product information by typing the keyword, therefore, companies must position their own product well, conduct network packaging of network marketing products, ensure that they can enter consumers' sight from the rich network commodities, sparking consumers to buy them. If companies can not place goods in the appropriate classification, it is likely to long-term or even never be able to enter consumers perspective and let alone cause buying behavior of.

\section{Well-designed web interface}

Networking sites interface is a major component of the consumer first impression and a well-designed interface help consumers produce the desire of browsing and buying. Some psychology information shows that the first three seconds of customers opening interface is the critical period to determine whether the customer will buy or not. Therefore, it is very significant to provide a good browsing operating experience to encourage customers to complete online shopping behavior through rational designation.

\section{Create a professional services team}

The current social trend is fine and diversified. If companies want to get attention and loyalty of consumers, good pre-sales and post-sales are indispensable elements. Because in the network platform, customers can experience many businesses service models at the same time. Because of the virtual of network, it's difficult for customers to distinct product quality accurately, timely and 
effectively, which makes network marketing customer service an important factor in judging the enterprise. By creating a professional Internet service team and providing full three-dimensional shopping guide service in the entire shopping process, so customers can get respect and attention, and we are able to effectively meet customers' needs as well as solve customers' problems, which is an important measure of training long-term customers. A number of market researches also showed that customers usually prefer to transact again with businesses already bought production.

\section{Conclusion}

In today's society where the network is so popular, we can say that Internet business model is the only way for the development of commodity markets. If companies want to survive, you can not avoid competition in this market. With the growing coverage and improvement of mobile terminal service surface, the Internet market will occupy a more and more important role in the company's sales module. And in order to fully take advantage of this market and grasp the development of the initiative, we must sufficiently understand its essence, utilize the characteristics of this market on the basis of understanding, so as to fully grasp the market dynamics. In this paper, through multiple analysis of characteristics of consumer psychology and consumer ability of consumer groups, network marketing platform,etc., the authors precisely describe marketing characteristics that Internet market is different from traditional marketing and made some deal strategy combined with their thinking, hoping to help companies better adapt to the Internet market environment and achieve better development.

\section{References}

[1] He Wei, Zhang Xi. Discussion on Small and Beautiful Trend of Enterprise Development [A]. Nanjing Science and Engineering University; Coventry University, Nanjing Science and Engineering University Journal. 2013 Vol.37 Supp (total 190) [C] Nanjing Science and Engineering University, Coventry University, UK: 2013: 4.

[2] Zhang Yi. The Corporate Culture Construction Strategy Research of Guangxi Mobile in mobile Internet Era [D]. Beijing University of Posts and Telecommunications, 2012.

[3] How to Become Internet Era Companies [N]. Qingdao Daily, 2012-03-30005.

[4] Wen Chihong. The Affecting Mechanism of Information to Enterprises Competitiveness and the Choice of Informational Strategy[D]. Jilin University, 2010.

[5] Jiang Qiangui. Learn Haier to Endeavor to Explore New Management Mode in Internet Era [A]. Confederatio-n of Chinese Enterprises, SASAC Enterprises Reformation Bureau, Industrialization and Informational Industrial Policy and Minor Enterprises, 2012:16. 